\title{
Ensino Baseado em Simulação na Formação Continuada de Médicos: Análise das Percepções de Alunos e Professores de um Hospital do Rio de Janeiro
}

\section{PALAVRAS-CHAVE \\ - Tecnologia Educacional; \\ - Ensino Baseado em Simulação; \\ - Educação Médica.}

\section{KEYWORDS}

- Educational Technology;

- Simulation-Based Learning;

- Medical Education.

\section{Simulation-Based Learning in Continuing Medical Education: Analysis of Student and Teacher Perceptions of a Hospital in Rio de Janeiro}

Alessandra Sá Simões Dourado ${ }^{I}$ Tais Rabetti Giannella ${ }^{I}$

\begin{abstract}
RESUMO
Nos últimos anos, o ensino baseado em simulação (EBS) tem sido cada vez mais utilizado na educação em saúde e especialmente na educação médica. Este estudo teve como objetivo investigar as potencialidades e desafios do EBS no contexto de um curso de formação continuada de médicos: Curso em Ressuscitação Cardiopulmonar (RCP) Avançado. A coleta de dados foi realizada por meio de observação de campo, entrevistas com professores e aplicação de questionários aos alunos do curso. Para análise das percepções dos participantes, adotou-se a análise de conteúdo temática. Os resultados apontaram quatro principais potencialidades e desafios do EBS para a formação médica: articulação entre teoria e prática; o erro como oportunidade de aprendizagem; relação entre mundo virtual e mundo real; fortalecimento do trabalho em equipe. Acredita-se que este trabalho possa contribuir com a discussão acerca da utilização do EBS na educação médica, assim como indicar pontos favoráveis e desafios de sua implementação, revelando a importância de pesquisas que aprofundem as questões pedagógicas envolvidas no percurso de aplicação desta metodologia.
\end{abstract}

\begin{abstract}
In recent years simulation-based learning $(S B L)$ has been increasingly used in health care training and especially in medical education. This study aimed to investigate the potential and challenges of SBL in the context of a continuing training course for physicians: Advanced Course in Cardiopulmonary Resuscitation. Data was collected through field observations, interviews with teachers and questionnaires to students on the course. The perceptions of the participants were analyzed through thematic content analysis. The results indicated four main possibilities and challenges for SBL medical training: linking theory and practice; learning through trial and error; the relationship between the virtual world and real world; strengthening teamwork. It is believed that this study can make an important contribution to the discussion about the use of SBL in medical education and indicate favorable aspects and challenges of its implementation, thereby revealing the importance of research into the pedagogical issues involved in applying this methodology.
\end{abstract}




\section{INTRODUÇÃO}

O presente artigo resulta de pesquisa desenvolvida durante a elaboração de dissertação e busca compreender os desafios e potencialidades do Ensino Baseado em Simulação (EBS) com o uso de manequins na formação médica. Partindo da visão de que o uso de tecnologias educacionais é um processo que depende do contexto de sua aplicação e dos atores que a utilizam $^{1,2}$, este trabalho apresenta aspectos ligados ao estudo de um caso particular: o curso de atualização em RCP avançado aplicado a médicos da Rede D'Or São Luiz, na cidade do Rio de Janeiro. Embora se concentre num contexto específico de aplicação do EBS, tendo como foco o acompanhamento de um curso e a análise das percepções dos docentes e alunos envolvidos, acredita-se que este estudo, cujos resultados são parcialmente apresentados no presente artigo, poderá contribuir com a construção de conhecimento sobre as questões pedagógicas que permeiam o desenvolvimento desta metodologia, principalmente em processos de educação médica continuada.

Como se pode observar na literatura ${ }^{3}$, o EBS já é bastante utilizado na área da saúde, especiamente na formação médica. De maneira geral, percebe-se que a maioria dos estudos tem como principal objetivo buscar evidências da eficácia do uso da simulação com o emprego de manequins no que diz respeito à aprendizagem dos alunos, por meio da aplicação de pré- e pós-testes aos estudantes. Embora este corpo de estudos venha reforçando os pontos positivos do uso de manequins na formação médica, poucos discutem os aspectos cognitivos e de aprendizagem que fundamentam sua aplicação. Além disso, como apontam Gomez et al. ${ }^{4}$, o avanço tecnológico na área da simulação nem sempre tem sido acompanhado de reflexões sobre as propostas didático-pedagógicas de sua implementação como metodologia de ensino-aprendizagem.

Historicamente, o ensino médico tem sido pioneiro na adoção de novas metodologias e tecnologias educacionais². Considerando que a atuação do médico requer domínio de conhecimentos e habilidades específicas - como a comunicação com o paciente, o exame físico, o raciocínio clínico e a execução de medidas diagnósticas e terapêuticas ${ }^{5}$ - e que tem a peculiaridade de ocorrer em contextos que exigem integração de diferentes saberes ${ }^{6}$, os processos de formação têm incorporado o uso de metodologias ativas de ensino e a prática em serviço como elementos fundamentais da aprendizagem.

Diante desses desafios, o EBS tem sido utilizado como uma metodologia que se caracteriza pelo aprendizado ativo em ambiente livre de risco, no qual se pode construir o conhecimento, a habilidade técnica, a comunicação, a liderança e o trabalho em equipe $e^{7}$. Neste contexto, a simulação médica apresenta-se como uma estratégia de ensino potencial, por permitir que a aprendizagem ocorra em ambiente seguro, possibilitando a demonstração de múltiplas patologias e facilitando que conhecimentos e habilidades sejam experimentados tal como na prática clínica ${ }^{8}$.

$\mathrm{Gaba}^{9}$ (p. 2) define a simulação no ensino em saúde como um "processo educativo que substitui o encontro com o paciente real por modelos artificiais, atores ou pacientes virtuais". Desta forma, o EBS ajuda os estudantes a desenvolver a habilidade de reconhecer as próprias limitações e lacunas em seu processo de aprendizagem sem colocar o paciente em risco $^{10}$.

Diante de tais dados, nossos objetivos foram analisar as potencialidades e desafios do EBS com uso de manequins, com base no acompanhamento do curso de Atualização em RCP Avançado e das percepções da equipe docente (coordenador e professores) e alunos envolvidos.

Se, de fato, foi possível constatar que é crítica a necessidade de ampliar as informações sobre o uso de simuladores de pacientes como metodologia de ensino-aprendizagem, pois poucos trabalhos articulam as visões de professores e alunos a fim de evidenciar as dificuldades e os desafios desta metodologia de ensino ${ }^{11}$, acreditamos que o presente artigo poderá incentivar novas pesquisas sobre a utilização do EBS na área da saúde de maneira a estender seu lastro de aplicação.

\section{MATERIAL E MÉTODOS}

O estudo foi realizado no contexto do curso Atualização em RCP Avançado, oferecido pelo Centro de Treinamento Avançado Rede D'Or São Luiz, localizado no Rio de Janeiro, e teve início após aprovação da Comissão Nacional de Ética em Pesquisa (CAAE: 11840712.5.0000.5249). O curso, realizado nos dias 4 e 5 de maio de 2013, teve como objetivo capacitar médicos dos hospitais da Rede D'Or São Luiz para aplicar eficientemente a reanimação cardiopulmonar básica e avançada. Este contexto foi escolhido por adotar a metodologia de EBS há quatro anos, por meio de resolução e discussão de casos clínicos, envolvendo conhecimento clínico e trabalho em equipe. Foram sujeitos da pesquisa 13 médicos da Rede D'Or São Luiz (alunos do curso), o coordenador do curso e três professores.

Para analisar as percepções da equipe docente em relação às potencialidades e aos desafios do EBS na formação médica, foram realizadas entrevistas semiestruturadas. Aos alunos foi aplicado, no final do curso, um questionário semiaberto composto por 12 questões.

Além desse material, foram utilizadas para análise notas de campo, registradas por meio da observação das aulas do curso, a fim de relacionar o contexto observado com as perspectivas dos participantes. 
Após transcrição das entrevistas e digitação das respostas dos questionários, adotou-se o método de análise de conteúdo temática para análise das percepções dos participantes, que seguiu as etapas básicas: pré-análise; descrição, exploração e interpretação dos dados ${ }^{12}$.

A aplicação deste procedimento analítico resultou em quatro núcleos temáticos que refletiram as principais potencialidades e desafios do EBS identificados no presente estudo: articulação entre teoria e prática na formação médica, o erro como oportunidade de aprendizagem, relações entre mundo virtual e mundo real, e fortalecimento do trabalho em equipe.

De maneira a preservar o anonimato dos participantes, adotou-se o seguinte código, que será utilizado para ilustração de suas falas: (P) identifica professor, (A) aluno; a numeração corresponde à ordem alfabética dos nomes de alunos e professores.

\section{RESULTADOS}

\section{Articulação entre teoria e prática na formação médica}

Com a análise dos registros de campo, verificou-se que o potencial do EBS no que diz respeito à articulação entre teoria e prática pôde ser caracterizado em diferentes situações observadas. Notou-se, por exemplo, como conceitos relacionados a diferentes áreas de conhecimento, usualmente ensinados de forma isolada, puderam ser resgatados na resolução dos problemas vivenciados. Além disso, o fato de os alunos poderem articular diferentes conhecimentos e habilidades, dependendo do cenário exposto, representou mais do que uma simples aplicação de protocolos, uma vez que estes puderam debater cada situação com o grupo.

Estas questões também foram citadas por professores e alunos, que reforçaram o potencial do EBS para o ensino-aprendizagem dos processos de diagnóstico e raciocínio clínico:

"[...] O aluno se vê diante dessa situação que é obrigado a resolver baseado no guideline que já conhece e, com isso, consegue desenvolver o raciocínio clínico de maneira clara, modificando as situações de acordo com a necessidade [...]". (P1) "Os simuladores nos dão uma ótima prática, quase real, nos colocando frente às dificuldades diárias que temos com pacientes". (A8)

Os professores destacaram que no EBS os alunos colocam diferentes conceitos em ação, refletindo e sanando dúvidas no decorrer da atividade:

“[...] Na verdade, quando você vai simulando e criando casos, vão surgindo dúvidas, você vai aguçando o questionamento sobre coisas que começam na própria fisiologia [...] A simulação tem um contexto bastante completo, que gera ação $e$ discussão acerca do doente como um todo, sobre o processo patológico, o processo fisiológico". (P2)

Percebe-se, também, principalmente na fala dos alunos, certa ênfase nos benefícios desta metodologia no que se refere à oportunidade de repetição e memorização dos protocolos.

$$
\begin{aligned}
& \text { "A prática ajuda na memorização da teoria [...] ajuda a fixar } \\
& \text { os guidelines". (A4) }
\end{aligned}
$$

Se, por um lado, isto pode ressaltar uma visão de aprendizado mecânico, por outro, não se pode negar a complexidade desta atividade, que requer rápido e preciso processo de raciocínio e tomada de decisão:

"[...] este tipo de procedimento exige atendimento de alto desempenho, ou seja, a identificação rápida do cenário, a agilidade na tomada de decisão, o acionamento de suporte, a execução de massagem cardíaca de alta qualidade, com a técnica correta e o mínimo de interrupções possíveis, passando pela desfibrilação precoce e pelo uso correto das drogas, até os cuidados pós-retorno da circulação espontânea [...]". (coordenador)

\section{O erro como oportunidade de aprendizagem}

Como destacado pelos professores, o potencial desta metodologia de promover o contato com situações de emergência sem trazer riscos ao paciente envolve não apenas a prática de repetição de procedimentos, mas a oportunidade de vivenciar casos variados e que demandam raciocínios e atitudes diferentes.

“[...] A gente treina aqui cenários de emergência médica, talvez aqueles que mexem mais com as pessoas porque envolvem parada cardíaca ou iminência de parada. E quanto mais conseguirmos nos aproximar desse cenário, que é estressante e envolve diferentes conhecimentos e habilidades, no qual as pessoas ficam nervosas, mais chance tem de a pessoa na vida real conseguir desempenhar aquilo que propõe o modelo teórico $[\ldots]^{\prime \prime} .(P 3)$

Os alunos citaram as vantagens do retorno imediato ao erro e às dúvidas, por parte do professor ou da equipe, o que promove maior segurança para a prática profissional. 
"O treinamento em bonecos é essencial para reduzir os erros médicos/profissionais de saúde [...] temos a oportunidade de feedback imediato". (A7)

“Os simuladores nos dão uma ótima prática, quase real, nos colocando frente às dificuldades diárias que temos com os pacientes, trazendo maior segurança para a prática". $(A 8)$

\section{Relações entre o mundo virtual e o real}

Aproveitar o erro como oportunidade de aprendizagem além de favorecer a visualização, manipulação e interpretação de situações complexas - é uma das potencialidades do EBS que pode ser explorada na relação entre mundo virtual e real. No caso específico, este potencial resulta do uso de manequins associados a casos clínicos na construção de cenários que se assemelham a situações do cotidiano da prática médica. Ao vivenciarem os cenários simulados, os alunos puderam reforçar e corrigir conhecimentos/habilidades previamente aprendidos e, ao mesmo tempo, projetar novas situações.

"[...] durante a simulação, eu tenho a capacidade de vivenciar todas as vantagens e desvantagens de qualquer manobra, simulando casos reais que me permitem estar mais perto da realidade que vou encontrar". (P2)

"Os simuladores são fundamentais para mimetizar essas situações de emergência e reforçam que os algoritmos devem estar bem compreendidos para poder ser aplicados". $(A 3)$

Se, por um lado, o virtual auxilia a elaboração do raciocínio, por outro, os professores relataram se deparar com a dificuldade dos alunos em vivenciar a simulação como um ambiente real, o que pode levá-los a assumir dois comportamentos críticos. No primeiro, o aluno não se envolve por ver à sua frente um "boneco" e por isso não consegue fazer daquele momento de simulação uma chance de aprendizagem a ser replicada numa situação real:

"[...] por estar numa área de treinamento, o aluno fica relaxado, se desconcentra, brinca e às vezes não tem o mesmo desempenho que teria se fosse na vida real. Não se esforça porque sabe que aquilo é um treinamento". (P3)

No segundo, ele se sente impactado pelo cenário e pela presença do manequim, por não estar habituado a esse tipo de metodologia e, nesse caso, também não consegue participar de maneira efetiva:

"[...] o aluno se impacta tanto com o boneco que chega a não querer tocar, manusear numa situação crítica". (P2)

Ainda no que diz respeito a esta relação - mundo real/cotidiano e mundo simulado/virtual -, destaca-se a reflexão de um dos professores, que traz um contraponto ao que muitos autores reforçam sobre a possibilidade de o EBS trazer frieza e tecnicidade aos processos educativos:

"Eles não aproveitam a oportunidade que têm no contato com
o doente para o aprendizado humanitário. É olhar para o do-
ente não como uma doença, mas como um ser humano amplo,
holístico, no qual você tem que abordar aspectos biopsicos-
sociais. Quando você oferece a ele esse conhecimento técnico
no ambiente de simulação, ele já não busca mais avidamente,
naquele contato com o doente, o conhecimento técnico. Ele
aplica o conhecimento técnico e elabora o conhecimento hu-
manitário, que eu não consigo fazer no manequim, porque eu
dependo de uma interação". (P1)

Na visão desta professora, a oportunidade da execução e repetição mecânica de muitos dos procedimentos pode satisfazer a necessidade dos alunos de vivenciar estas práticas, fazendo com que eles possam se dedicar a questões afetivas e interpessoais da relação médico-paciente nos ambientes reais.

\section{Fortalecimento do trabalho em equipe}

Os alunos trabalharam em grupos durante todo o curso e passaram por todos os papéis dentro da equipe de ressuscitação. Para cada caso clínico, um aluno era escolhido líder, e os membros da equipe trocavam de função. Desta forma, além dos conhecimentos e habilidades específicas de cada função ventilação, entubação, compressões torácicas, desfibrilação e administração de medicamentos -, os alunos puderam exercitar o papel de liderança, responsável pela condução das ações e integração de todos membros da equipe, assim como pela resolução do caso clínico exposto.

"No contexto emergencial, enfatiza-se muito a questão da liderança da equipe de atendimento como um elemento fundamental na organização e otimização da dinâmica e dos diversos componentes que integram um atendimento bem-sucedido". (coordenador) 
Professores e alunos destacaram as vantagens da metodologia de EBS para a vivência do trabalho em equipe, um tipo de conhecimento difícil de ser aprendido sem a experiência prática. Além da oportunidade de vivenciar a troca de papéis, houve destaque para o momento de discussão, quando a turma pôde rever as situações, compreender os erros, compartilhar experiências e tirar dúvidas.

\begin{abstract}
"No final de cada cenário ocorre um debriefing do caso, permitindo a autoanálise do aluno líder e dos outros envolvidos sobre as ações adotadas". (P3)

"No EBS trabalhado em equipe aprende-se com mais didática, é mais dinâmico, e o conteúdo é mais bem fixado".

\section{DISCUSSÃO}

A metodologia de EBS adotada no curso de RCP permite que os alunos se deparem com um problema, criem hipóteses com base nos dados clínicos apresentados e, apoiados em conhecimentos prévios, tentem chegar ao diagnóstico a fim de escolher a melhor conduta a adotar. Nesse caminho, vão tomando decisões e, por meio do feedback do manequim, e também dos professores, às suas intervenções, podem verificar se estão indo pelo caminho correto ou não. Desta forma, esta metodologia pode auxiliar o aluno a aprender a raciocinar clinicamente, articulando teoria e prática.

Este modelo de aprendizado vai ao encontro das necessidades apontadas na literatura de formar um médico capaz de raciocinar criticamente a fim de analisar os problemas e tomar decisões fundamentadas em sua própria avaliação ${ }^{13}$. Como discute Stamm ${ }^{14}$, a maior parte das escolas médicas não tem dado a devida atenção ao aprendizado do raciocínio e diagnostico médico, ignorando que essas habilidades cognitivas específicas possam ser ensinadas, mesmo que a literatura das últimas décadas demonstre o contrário.

Nas entrevistas, os professores reforçaram o potencial do EBS como estratégia para desenvolvimento do processo de raciocínio clínico dos médicos em formação. Além disso, ressaltando a necessidade de renovar currículos e estratégias de ensino-aprendizagem em busca de maior articulação entre teoria e prática, um dos professores criticou o ainda predominante modelo de formação médica:

\footnotetext{
"Eu acho que até o terceiro ano a faculdade é muito parecida com o colégio. Você tem aula básica. Mas no quarto ano, e principalmente no quinto e sexto, que é um internato, você tem uma formação prática. Ele senta, tem aula de hiperten-
}

são, diabetes [...] Aí, quando vai para a enfermaria ver o doente, não sabe o que tem que prescrever, não sabe que perguntas tem que fazer na anamnese, que dados tem que procurar no exame físico". (P3)

Como discutem Fernandes et al. ${ }^{15}$, de acordo com as Diretrizes Curriculares Nacionais, os cursos de Medicina devem apresentar um currículo baseado em competências, que tem por objetivo formar profissionais críticos e capazes não somente de solucionar problemas, mas também de melhorar os contextos sociais, por meio de uma atuação responsável. Para isso, o ensino deve visar ao aprendizado não só de conhecimentos, mas de habilidades e atitudes.

Nesse sentido, existem metodologias de ensino que procuram tornar esse processo de ensino-aprendizagem mais integrado e adequado ao perfil profissional que se quer formar. Dentre elas, a Aprendizagem Baseada em Problemas (ABP) vem se destacando, sendo avaliada por pesquisas em vários países ${ }^{16}$. Sobre essa questão, um dos professores aponta que a ABP aliada ao EBS pode auxiliar na integração do conhecimento e na formação do raciocínio clínico:

"Então, eu acho que depois da formação básica [...] a abor-
dagem devia ser Problem-Based Learning [...]. O interno vêe
o doente, tem que olhar a anamnese, entrevistar, examinar e
montar um raciocínio em cima daquilo. Montar os problemas
que o paciente tem [...] e como vai interpretá-los [...] Isso per-
mite a ele, com base num paciente, estudar vários assuntos
diferentes, desde a fisiologia, passando pelo diagnóstico até a
terapêutica". (P3)

Para o professor, o cenário da simulação permite integrar os conteúdos aprendidos com a prática, tornando o EBS uma ferramenta importante na educação médica:

\footnotetext{
"Isso funciona melhor no cenário da simulação. A gente usa exemplos reais. Um doente e os alunos entrevistando. Podemos utilizar situações pouco comuns ou tão urgentes que você não pode ensinar na hora, mas com o manequim é possível criar esse ambiente. Por isso acho importante a utilização do EBS na educação médica". (P3)
}

O principal desafio apontado pelos professores quanto à sua prática com o EBS diz respeito à necessidade de lidar com alunos com conhecimentos e experiências diferenciados, principalmente pelo fato de a metodologia promover a articulação de conceitos de diferentes áreas da Medicina: 
"O momento que exige maior maturidade é lidar com a diversidade de conhecimento e experiência dos alunos, muitas vezes formando grupos extremamente heterogêneos e que demandam grande flexibilidade do instrutor para adequar cenários e discussões" [...] (coordenador)

Este aspecto é discutido na literatura, que aponta que o sucesso do EBS depende da mudança de papéis e atitudes por parte de professores e alunos ${ }^{10}$.

Professores e alunos foram unânimes em afirmar que o EBS favorece a aquisição e o aprimoramento de conceitos e habilidades práticas. Entretanto, a literatura aponta que não é possível fazer essa afirmação com base apenas na comparação entre pré- e pós-teste ou na avaliação do aluno por meio de um check-list de ações realizadas no manequim, ressaltando a importância de desenvolver estudos posteriores com o profissional treinado, em situação real. A literatura mostra que os estudantes que têm contato mais cedo com a prática simulada conseguem adquirir um arcabouço sólido de conhecimentos e habilidades fundamentais em semiotécnica e comunicação, além de estimular o raciocínio crítico e reflexivo, por se tratar de uma aprendizagem mais realista e significativa $^{17}$.

No que diz respeito à potencialidade do EBS de promover um processo educativo que reconheça o erro como oportunidade de aprendizagem, equipe docente e alunos apontaram, dentre as vantagens desta metodologia, a possibilidade de alunos treinarem cenários diversificados sem riscos para o paciente, reduzindo a ocorrência de eventuais falhas no futuro do profissional:

"[...] o aluno pode errar um número ilimitado de vezes sem que isso resulte em efeitos deletérios para um paciente real". (coordenador)

“O treinamento em bonecos é essencial para reduzir os erros médicos/profissionais de saúde". (A7)

Como discutem Varga et al. ${ }^{18}$, ao se deparar com situações simuladas, o estudante tem a oportunidade de aprender fazendo. Refletindo sobre o erro, constrói seu aprendizado por meio da identificação de lacunas de conhecimento e fundamenta cognitivamente suas capacidades.

No campo da educação, percebe-se que houve uma grande mudança em relação ao significado do erro ${ }^{19}$. Em geral, o erro era observado pelo professor como um indicador de mau desempenho do aluno, sem jamais ser utilizado para o redimensionamento do ensino ${ }^{20}$. Hoje, o erro pode ser visto como um processo de maturidade e oportunidade para o aluno desenvolver a capacidade de pensar e resolver problemas, criar hipóteses e, assim, chegar a um novo conhecimento. Logo, o professor tem o papel fundamental de instigar os alunos a refletir sobre seus erros, estimulando-os a raciocinar criticamente $^{19}$.

Na análise dos resultados, observou-se que no ambiente simulado os erros permitem ensinar sobre suas implicações e corrigir desvios, pois não causam danos a pacientes reais e podem ser discutidos, diferentemente da aprendizagem em cenário clínico real, no qual o professor interfere para evitar danos ao paciente ${ }^{21}$. Ao término de cada cenário, o erro é discutido em forma de debriefing. Para Flato e Guimarães ${ }^{7}$, esse é o momento-chave para a efetividade pedagógica da simulação, pois estimula a reflexão dos alunos, uma vez que o erro pode ser revisado abertamente, com menor sentimento de culpa, mesmo quando as decisões tomadas resultam em morte do paciente simulado ${ }^{21}$.

\begin{abstract}
"Ao final de cada cenário, ocorre um debriefing do caso, permitindo a autoanálise do líder e dos envolvidos, a discussão entre eles, a participação ativa de todos com a informação gerada dentro do ajustamento do raciocínio lógico de atendimento". (coordenador)
\end{abstract}

Esta fala do coordenador demonstra a valorização dos momentos de discussão e análise dos casos vivenciados, quando os conhecimentos mobilizados podem ser resgatados, e possíveis erros debatidos. Isto é reforçado por um dos alunos, que aponta a importância de aprender no momento da ação, quando as dúvidas surgem a partir da vivência:

"A maioria das dúvidas surge quando tentamos exercer".

A perspectiva de "aprendizagem orientada pela atividade $^{\prime 22,23}$ é amplamente discutida no campo educacional, que compreende que os processos de "aprender" e "fazer" são inseparáveis e motivados por intenções. Tal perspectiva, também relacionada à necessária articulação teoria-prática, concebe que o processo de construção de conhecimento se ancora nas experiências prévias dos alunos e é orientado por metas que devem ser incorporadas à atividade educativa. Reforça, também, que a aprendizagem se dá numa relação dinâmica entre conhecimentos internalizados e ações concretas, internalização-externalização $0^{23}$, "processo pelo 
qual os indivíduos transformam seus entendimentos sobre a responsabilidade para com as atividades por meio de suas participações"(p.74) ${ }^{22}$. Assim, um dos professores reforça este potencial do EBS:

\begin{abstract}
"Na verdade, quando você vai simulando e criando casos, vão surgindo dúvidas, você vai aguçando o questionamento sobre coisas que começam na própria fisiologia [...] A simulação tem um contexto bastante completo, que gera discussão acerca do doente como um todo, sobre o processo patológico, o processo fisiológico" (P2).
\end{abstract}

As potencialidades de se explorar a sinergia da relação entre mundo virtual e real foram ressaltadas por professores e alunos. Como discutem Varga et al. ${ }^{18}$, a partir da vivência de situações simuladas, os estudantes são estimulados a ressignificar seus conhecimentos construindo novos saberes.

Lévy $^{24}$ ressalta que a capacidade de reproduzir o ambiente e suas reações pode desempenhar um papel fundamental na aprendizagem e que podemos considerar a simulação como uma ferramenta potente de ajuda ao raciocínio, já que a manipulação dos parâmetros e a simulação das diversas circunstâncias envolvidas proporcionam uma espécie de intuição sobre as diferentes relações presentes no modelo estudado. Neste sentido, os sujeitos da pesquisa consideram que o EBS pode favorecer o desenvolvimento do raciocínio clínico para a resolução dos casos propostos:

"O manequim, na grande maioria das vezes, simula com perfeição a situação que você está propondo, e o aluno se vê diante dessa situação que ele é obrigado a resolver, baseado no guideline que ele já tem como conhecimento prévio e, em cima disso, ele consegue desenvolver o raciocínio clínico de maneira clara". (P1)

Segundo Lévy ${ }^{24}$, o virtual é, de certa forma, uma antecipação possível do real. Assim, ao se aproximar da realidade, o virtual agrega características e cenários que permitem aos alunos se identificarem com esse espaço 25 . Sobre esse aspecto, um dos professores cita a importância de criar um cenário que se aproxime ao máximo da vida profissional cotidiana:

\footnotetext{
“Você tenta criar um ambiente, um estilo de paciente, uma patologia que o aluno vá ver no dia a dia, então a simulação é muito interessante nesse sentido". (I3)
}

O virtual é fonte indefinida de atualizações, o que traz para o processo educativo a liberdade de experimentação e manipulação de diferentes situações sem os riscos da vida real $^{25}$. Para os professores, a liberdade de atuação sem trazer riscos ao paciente real experimentada pelo virtual facilita a aprendizagem:

"[...] passeando pelos guidelines, modificando as situações de acordo com a necessidade de abordar o conhecimento, de maneira isolada ou conjunta, você cria um ambiente realístico e amplo dentro do assunto que você quer abordar". (P1)

Ao relatar os desafios do EBS, a equipe docente destacou que é difícil conseguir total imersão dos alunos no ambiente simulado, fazendo com que, muitas vezes, sua dedicação não seja semelhante àquela desempenhada numa situação de risco real. De modo compatível com o que é discutido na literatura ${ }^{26}$, os professores indicaram como possíveis formas de superar este desafio o planejamento cuidadoso dos casos e do ambiente e o preparo da equipe para mediar as situações estudadas.

Na opinião de um dos professores, o EBS com uso de manequins pode suprir a necessidade e o entusiasmo dos alunos em treinar as habilidades técnicas, permitindo que, no atendimento cotidiano, se dediquem ao desenvolvimento de um cuidado ampliado e humanista. Essa perspectiva da professora indica uma possível visão alternativa à de diversos autores que criticam o uso de tecnologias no ensino por poderem tornar os espaços menos humanizados ${ }^{27}$ e distantes da realidade, ou que acreditam que o uso de simulações pode simplificar demasiadamente situações complexas do dia a dia ${ }^{28}$.

Como discute $\operatorname{Ramos}^{25}$ (p. 108):

O virtual, ao aproximar-se da realidade, agrega características e cenários que permitem aos jogadores identificarem-se com esse espaço; ao mesmo tempo, as regras e valores podem ser diferentes daqueles que temos na vida cotidiana, e as consequências também ficam resguardadas ao mundo virtual.

Assim, levando em conta a visão da docente, se os alunos aproveitam o aprendizado com manequins para desenvolver e aprofundar suas habilidades técnicas, isto não quer dizer que esta atitude reforçará um futuro comportamento profissional pautado num atendimento procedimental.

Esta discussão pode ser corroborada por duas questões fundamentais relacionadas ao uso de tecnologias na educação: (1) não é a tecnologia em si que levará a um aprendizado crítico ou futura atuação profissional em saúde ampliada e 
integral2; (2) o ensino baseado em tecnologias é mediado e, portanto, a visão e o papel docente na condução do processo educativo terão forte implicação na contribuição desta atividade para a formação dos alunos ${ }^{1}$.

Finalmente, na análise dos resultados, destaca-se o fortalecimento do trabalho em equipe como importante potencialidade do EBS na formação médica.

O treinamento em equipe é uma preocupação quando se trata de educação médica, uma vez que métodos tradicionais de ensino, por meio de aulas expositivas e avaliação de conhecimento por testes escritos, são insuficientes para garantir competência, qualidade e segurança no atendimento de pacientes críticos ${ }^{7,29}$. Metodologias ativas têm privilegiado espaços de colaboração e compartilhamento de saberes, encorajando os estudantes a trabalhar juntos em atividades nas quais o professor não é a única fonte de conhecimento.

Vários trabalhos evidenciam a relevância da utilização do EBS no treinamento de equipes ${ }^{30,31,32}$. Em um estudo realizado por Garret et al. ${ }^{30}$, os alunos apontaram o trabalho em grupo na prática diária como confuso e disseram que por isso preferem trabalhar sozinhos ou com um parceiro apenas. Para os autores, a simulação auxilia na conscientização dos profissionais sobre a importância da equipe interdisciplinar na assistência ao paciente. Ainda sobre este aspecto, Masielo ${ }^{33}$ ressalta que os profissionais de saúde vêm sendo treinados por muitos anos a atuar individualmente, enquanto o cuidado ao paciente demanda colaboração entre profissionais.

Durante o curso de RCP, foi possível perceber que, ao expor um caso clínico, o professor oferece ao aluno líder do cenário prático a chance de buscar conhecimentos prévios para que possa empregá-los na resolução do problema; ao mesmo tempo, permite que os outros alunos envolvidos no cenário colaborem na construção desse novo conhecimento necessário à finalização do caso clínico. $\mathrm{O}$ rodízio nas equipes oferece a todos os alunos a oportunidade de vivenciar os diferentes papéis envolvidos nos cenários. Assim, professores e alunos reforçaram o potencial desta metodologia para o treinamento de habilidades de comunicação e liderança, tão difíceis de desenvolver sem a vivência prática.

Para os professores, contribuir com o processo de aprendizagem colaborativa é uma atividade que traz novos desafios para suas práticas. Como indicou o coordenador, grupos heterogêneos de alunos demandam flexibilidade dos instrutores para adequar os cenários e as discussões a fim de que todos possam aprender durante as estações práticas:

“[...] existem algumas características que julgo necessárias ao instrutor, como o domínio da condução de grupos, iden- tificando situações que precisam ser corrigidas de imediato (alunos dominadores, apáticos, estrela, dissipativos, com carências conceituais, etc.) e o domínio na condução de técnicas de debriefing". (coordenador)

Sobre a condução de grupos, Pazin Filho et al. ${ }^{33}$ apontam a importância de o instrutor identificar os alunos com características especiais, como o aluno com conhecimento avançado, o dominador, o que divaga, o tímido e aquele com prática antiga e viciada, e sugere atitudes para cada situação a fim de que todos tenham a oportunidade de compartilhar suas expertises e aprender uns com os outros.

\section{CONCLUSÕES}

O acompanhamento do curso de RCP e a análise das observações realizadas permitiram identificar os desafios e potencialidades pedagógicos do EBS ressaltados na literatura e situá-los quanto aos diferentes elementos educativos que os permeiam. Estes elementos observados foram reiterados com as análises das entrevistas efetuadas com a equipe docente e dos questionários aplicados aos alunos.

As falas dos professores sobre o EBS suscitaram a discussão de importantes desafios relacionados a esta metodologia, que envolvem o papel do professor, visões sobre o que é ensinar e aprender, e sobre a necessária renovação da prática docente e do atual modelo de formação médica. As falas dos alunos reforçaram pontos ligados aos benefícios deste tipo de metodologia para seus processos de aprendizagem, destacando especialmente a possibilidade de atualização e a construção de novos conhecimentos na área estudada, com base na projeção de situações ainda não vivenciadas por eles.

Assim como em outros trabalhos ${ }^{32,11}$, os alunos reconheceram o potencial do EBS como metodologia alternativa às habituais aulas expositivas, a qual permite maior dinâmica e aprendizado situado. Tanto professores como alunos chamaram a atenção sobre os desafios deste tipo de metodologia, que demanda dos docentes abertura para lidar com alunos com níveis de conhecimento e prática diferenciados. Assim, a articulação dos resultados resultou na identificação de quatro principais potencialidades e desafios do EBS: articulação entre teoria e prática; o erro como oportunidade de aprendizagem; relação entre mundo virtual e mundo real; fortalecimento do trabalho em equipe.

Acredita-se que este trabalho possa contribuir com a discussão acerca da utilização do EBS na educação médica, assim como indicar pontos favoráveis e desafios de sua implementação, revelando, com isso, a importância de pesquisas que 
aprofundem as questões pedagógicas envolvidas no percurso de aplicação desta metodologia.

\section{REFERÊNCIAS}

1. Pretto N. O desafio de educar na via digital: educações. Rev. Portuguesa de educação 2011; 24:95-118.

2. Struchiner M, Gianella TR. Aprendizagem e Prática Docente na Área da Saúde: Conceitos, Paradigmas e Inovações. Washington, D.C.: OPAS; 2005.

3. Fornaziero CC, Gil CRR. Novas tecnologias Aplicadas ao Ensino da anatomia Humana. Revista Brasileira de Educação Médica 2003; 27(2):141-146.

4. Gomez MV, Vieira JE, S Neto A. Análise do perfil de professores da área da saúde que usam a simulação como estratégia didática. Revista Brasileira de Educação Médica 2011; 35(2):157-162.

5. Troncon LEA. Utilização de pacientes simulados no ensino e na avaliação de habilidades clínicas. Medicina (Ribeirão Preto) 2007; 40(2):180-191.

6. Aguiar AC, Ribeiro ECO. Conceito e avaliação de habilidades e competência na educação médica: percepções atuais dos especialistas. Revista Brasileira de Educação Médica. 2010; 34(3): 371-378.

7. Flato UAP, Guimarães HP. Educação baseada em simulação em medicina de urgência e emergência: a arte imita a vida. Revista Brasileira de Clínica Médica 2011; 9(5):360364.

8. Berkenstadt H, Ziv A, Gafni N, Sidi A. The validation process of incorporating simulation-based accreditation into the anesthesiology Israeli National Board Exams. IMAJ 2006; 8:728-733.

9. Gaba DM. The future vision of simulation in healthcare. Qual Saf Healthcare 2004; 13(1):2-10.

10. Okuda Y, Bryson EO, Junior SD, Jacobson L, Quinones J, Shen B et al. The utility of simulation in Medical Education: What is the evidence? Mount Sinai Journal of Medicine 2009; 76:330-343.

11. Searl KR, Happell B, Vieth L, Eaton A. High fidelity patient silicone simulation: A qualitative evaluation of nursing students' experiences. Royal College of Nursing 2012; 19:77-83.

12. Bardin L. Análise de Conteúdo. Lisboa: Edições 70; 2004.

13. Costa NMSC. Docência no ensino médico: por que é tão difícil mudar? Revista Brasileira de Educação Médica 2007;31(1):21-30.

14. Stamm AMNF. Raciocínio clínico no diagnóstico médico. Florianópolis; 2007. Doutorado [tese] - Universidade Federal de Santa Catarina.
15. Fernandes CL, Filho AF, Gomes JMA, Filho WAP, Cunha GKF, Maia FL. Currículo baseado em competências na residência médica. Revista Brasileira de Educação Médica 2012; 36(1):129-136.

16. Gomes R, Brino RF, Aquilante AG, Avó LRS. Aprendizagem Baseada em Problemas na formação médica e o currículo tradicional de medicina: uma revisão bibliográfica. Revista Brasileira de Educação Médica 2009; 33(3):444-451.

17. Dornan T, Littlewood S, Margolis SA, Scherpbier A, Spencer J, Ypinazar V. How can experience in clinical and community settings contribute to early medical education? A BEME systematic review. Medical Teacher 2006; 8(1):3-18.

18. Varga CRR, Almeida VC, Germano CMR, Melo DG, Chachá SGF, Souto BGA et al. Relato de experiência: o uso de simulações no processo de ensino aprendizagem em medicina. Revista Brasileira de Educação Médica 2009; 33(2):291-297.

19. Motta A, Amorim MP. O lado positivo do erro no processo de ensino aprendizagem de matemática no terceiro ano do Ensino Médio. Revista Científica da Escola Superior Aberta do Brasil 2011;1(2): s/p.

20. Pinto NB. O erro como estratégia didática: Estudo do erro no ensino da matemática elementar. Campinas, SP: Papirus; 2000.

21. Ziv A, Wolpe PR, Small SD, Glick S. Simulation-based medical education: an ethical imperative. Academic Medicine 2003; (8):785.

22. Giannella TR. "A Teoria da Atividade como Abordagem Teórico-Metodológica para o Desenvolvimento e Análise de um Curso Virtual para Docentes Universitários: A Internet no Ensino Superior: Recursos e Aplicações". Rio de Janeiro; 2003. Mestrado [Dissertação] - Núcleo de Tecnologia Educacional para a Saúde, Universidade Federal do Rio de Janeiro.

23. Jonassen D. Activity Theory as a Framework for Designing Constructvist Learning Enviroments. Educational Technology Research and Development 1999; 47(1).

24. Lévy P. As Tecnologias da Inteligência: O Futuro do Pensamento na Era da Informática. Rio de Janeiro. Editora 34; 1996. p 208.

25. Ramos DK. Jogos eletrônicos e aspectos morais: a borda entre o real e o virtual. Filos. Educ., Caxias do Sul. 2013; 18(1):105-119.

26. Vázquez JAI, Núñes AR, Penas MP, Santos LS, García MC, Díaz MVB. Cost-efficiency assessment of advanced life support (ALS) courses based on the comparison of advanced simulators with conventional mannequins. BMC Emergency Medicine, 2007 [Capturado 02 fev. 2014]. Disponível em http:/ / www.biomedcentral.com/I471-227x/7/18. 
27. Schwonke CRGB, Filho WDL, Lunardi VL, Santos SSC, Barlem ELD. Perspectivas filosóficas do uso da tecnologia no cuidado de enfermagem em terapia intensiva. Revista Brasileira de Enfermagem 2011; 64(1).

28. Medeiros A, Medeiros CF. Possibilidades e Limitações das Simulações Computacionais no Ensino da Física. Rev. Bras. Ensino Fís., São Paulo 2002; 24(2).

29. Oliveira GS, Koifman L. Integralidade do currículo de medicina: inovar/transformar, um desafio para o processo de formação. In: Marins JJN, Rego S, Lampert JB, Araújo JGC, organizadores. Educação médica em transformação: instrumentos para a construção de novas realidades. São Paulo: Hucitec; Rio de Janeiro: Associação Brasileira de Educação Médica; 2004. p.143-164.

30. Garret BM, MacPhee M, Jackson C. Implementing high-fidelity in Canada: reflections on 3 years of practice. Nurse Education Today 2010; 31:671-676.

31. Turk DM, Krizmaric M, Blazun H, Skvarc NK, Kozelj A, Kokol P et al. Simulation in Medicine and Nursing first experiences in simulation centre at Faculty of Health Sciences University of Maribor. IFMBE Proceedings 2007; 16:716-718.

32. Masiello I. Why simulation-based team training has not been used effectively and what can be done about it. Adv in Health Science Education; 2011.
33. Filho AP, Schmidt A, Filipini C, Castro RBP, Rosa RM, Rosa MAOF et al. Simulação de pacientes: Cursos de Suporte de Vida ACLS, BLS e PALS na FMRP/ USP. Medicina, Ribeirão Preto 2007; 40(2,):204-212.

\section{CONTRIBUIÇÃO DOS AUTORES}

Alessandra Dourado participou da coleta e análise dos dados e da elaboração do artigo; Taís R. Giannella orientou a pesquisa e participou da análise dos dados e da redação do artigo.

\section{CONFLITO DE INTERESSES}

Os autores declaram não haver conflito de interesses.

\section{ENDEREÇO PARA CORRESPONDÊNCIA}

Centro de Ciências da Saúde/ Núcleo de Tecnologia

Educacional para a Saúde

Av. Brigadeiro Trompovski, sem número, Bloco A, sala 12

Fundão - Rio de Janeiro

CEP 21949-900 RJ

E-mail: alesadourado@gmail.com 